\title{
Life-threatening acute hyponatraemia induced by low dose cyclophosphamide and indomethacin
}

\author{
M.J. Webberley and J.A. Murray \\ Selly Oak Hospital, Raddlebarn Road, Selly Oak, Birmingham B29 6JD, UK.
}

\begin{abstract}
Summary: We report the case of a patient with multiple myeloma who developed acute lifethreatening water intoxication following treatment with oral indomethacin and low dose intravenous cyclophosphamide. We describe a possible drug interaction between these two drugs and recommend that they should only be used together with caution.
\end{abstract}

\section{Introduction}

Cyclophosphamide is an alkylating agent used extensively in the treatment of malignant disease and connective tissue disorders. Its recorded side effects include bone marrow depression, alopecia, mucositis, sterility, haemorrhagic cystitis and when, used in high doses, myocardial degeneration and severe water intoxication. We report the case of a man with multiple myelomatosis who developed life-threatening water intoxication following therapy with low dose cyclophosphamide $(<10 \mathrm{mg} / \mathrm{kg})$ and the nonsteroidal anti-inflammatory prostaglandin inhibitor, indomethacin.

\section{Case report}

A 68 year old male Sikh presented in October 1984 with lumbar and thoracic spine pain and anaemia. Subsequent investigations revealed a diagnosis of multiple myeloma of the IgG kappa type. Previous medical history included mastectomy of the left breast for adenocarcinoma several years before, and he was hypertensive, treated adequately with propanolol $80 \mathrm{mg}$ once daily. Renal function and serum calcium were normal at diagnosis (urea $3.9 \mathrm{mmol} / \mathrm{l}$, serum creatinine $81 \mu \mathrm{mol} / \mathrm{l}$, serum calcium $2.28 \mathrm{mmol} / \mathrm{l}$ ), and he was commenced on monthly cycles of melphalan (Medical Research Council Vth myelomatosis trial) and received radiotherapy for his bone pain. Because of prolonged neutropenia his treatment was altered to weekly intravenous injections of $500 \mathrm{mg}$ cyclophosphamide.

He tolerated the treatment well and this was discontinued in January 1986 following a good clinical and serological response. He was readmitted to hospital in September 1986 with a pathological fracture of the left

Correspondence: J.A. Murray, M.R.C.P., M.R.C.Path. Accepted: 11 May 1989 hip and serological progression of his disease.

His biochemistry was normal on admission (urea $6.7 \mathrm{mmol} / \mathrm{l}$, sodium $138 \mathrm{mmol} / \mathrm{l}$, creatinine $85 \mu \mathrm{mol} / \mathrm{l}$, serum calcium $2.43 \mathrm{mmol} / \mathrm{l})$. Indomethacin $50 \mathrm{mg}$ 8 hourly was prescribed for his pain and, whilst waiting for hip surgery, treatment for his myeloma was reinstituted. He was given a single bolus injection of cyclophosphamide $500 \mathrm{mg}$ intravenously and was maintained on oral hydration with 3 litres of fluid a day. However, 48 hours later he became restless and응 unwell with confusion and disorientation. His blood pressure rose from $130 / 80$ to $240 / 135 \mathrm{mmHg}$ and he developed severe pulmonary oedema. His biochemistry at this time showed a serum sodium of $108 \mathrm{mmol} / \mathrm{l}$, a potassium of $3.3 \mathrm{mmol} / \mathrm{l}$, a urea of $8.6 \mathrm{~mol} / \mathrm{l}$, serum osmolality of $247 \mathrm{mmol} / 1$ and urine osmolality of $563 \mathrm{mmol} / \mathrm{kg} \mathrm{H}_{2} \mathrm{O}$. Urinalysis was normal apart from a trace of albuminuria. In addition, a weight gain of $3 \mathrm{~kg}$ from time of admission had been noted. A diagnosis of acute water intoxication was made and he was placed on strict water deprivation. He received intravenous frusemide for his left ventricular failure, his betablocker was replaced by nifedipine and the indomethacin was discontinued. He made a good clinical and biochemical improvement with this treatment, although he remained confused for several days.

His biochemistry had normalized after 24 days and a successful left hip replacement was then performed. He was eventually discharged home on subcutaneous injections of $\alpha_{2}$-interferon with which he had made a very satisfactory response.

\section{Discussion}

This case is unusual in that features of acute water intoxication and salt retention were both present in our patient.

(C) The Fellowship of Postgraduate Medicine, 1989 
Severe hyponatraemia has been previously reported in patients treated with high dose cyclophosphamide $(30-40 \mathrm{mg} / \mathrm{kg}) .^{1-4}$ This complication has also rarely been seen in patients treated with more moderate doses $(20-30 \mathrm{mg} / \mathrm{kg}),{ }^{5}$ but to our knowledge there are no previous reports of life-threatening water intoxication following low dose cyclophosphamide therapy $(<10 \mathrm{mg} / \mathrm{kg})$.

Cyclophosphamide itself is pharmacologically inactive and has a half-life of between 3 to 11 hours, whilst the maximal anti-diuretic effect occurs between 11 and 14 hours consistent with the appearance in the circulation of the alkylating metabolites. ${ }^{2}$ Water intoxication, therefore, probably occurs either as a direct toxic effect of the alkylating metabolites on the renal tubules, an anti-diuretic hormone-like activity of these metabolites, or by direct stimulation of anti-diuretic hormone release (ADH) from the hypothalamus. ${ }^{1,2,4}$ Post-mortem examination performed on one patient who had received high dose cyclophosphamide showed loss of Herring bodies and degranulation of various hypothalamic neurosecretory organelles. ${ }^{4}$ However, other studies have shown that monitored serum ADH levels have not altered significantly during treatment with cyclophosphamide. ${ }^{5}$ In general, the nature of this complication has yet to be explained.

Indomethacin may also have contributed to the acute water intoxication by inhibition of the synthesis of prostaglandins $\mathrm{PgE}_{2}$ and $\mathrm{PgI}_{2}$ in the kidney, through blockade of the enzyme cyclo-oxygenase. ${ }^{6}$ Renal $\mathrm{PgE}_{2}$ and $\mathrm{PgI}_{2}$ have been shown to be important in maintaining water and electrolyte homeostasis along with renal blood flow. ${ }^{7,8}$ They have an inhibitory action on water and salt reabsorption in the kidney and have been shown to be important in the prostaglandin-mediated inhibition of anti-diuretic hormone on the distal tubule, ${ }^{9}$ thus providing a

\section{References}

1. Steele, T.H., Serpick, A.A. \& Block, J.G. Antidiuretic response to cyclophosphamide in man. $J$ Pharmacol Exp Ther 1973, 185: 245-253.

2. De Fronzo, R.A., Braine, H.C. \& Michael, D.P. Water intoxication in man after cyclophosphamide therapy. Ann Intern Med 1973, 78: 861.

3. De Fronzo, R.A., Colvin, P.M., Braine, H.C. et al. Cyclophosphamide and the kidney. Cancer 1974, 33: 483-490.

4. Harlow, P.J., DeClerck, T.A., Shore, N.A. et al. A fatal case of inappropriate ADH secretion induced by cyclophosphamide therapy. Cancer 1979, 44: 896-898.

5. Bressler, R.B. \& Huston, D.M. Water intoxication following moderate dose intravenous cyclophosphamide. Arch Intern Med 1985, 145: 548-549.

6. Vane, J.R. Inhibition of prostaglandin synthesis as a mechanism of action for aspirin-like drugs. Nature 1979, 231: $232-235$. probable site of drug interaction between indomethacin and cyclophosphamide. The antiprostaglandin effect of indomethacin may also have contributed to the features of acute salt retention and severe hypertension that developed in our patient. Inhibition of $\mathrm{PgE}_{2}$ and $\mathrm{PgI}_{2}$ by indomethacin has been shown to enhance sodium chloride reabsorption in the thick ascending limb of Henle. ${ }^{10}$ Similarly, intravenous infusions of indomethacin in patients who are hyponatraemic have been shown to produce peripheral vasoconstriction and increased systolic blood pressure, although this effect is not so dramatic in patients who are normonatraemic. ${ }^{11}$ In health, renal and peripherally produced $\mathrm{PgE}_{2}$ and $\mathrm{PgI}_{2}$ act as local vasodilators counteracting the pressor effect of noradrenaline and angiotensin $\mathrm{II} .^{12}$ But in patients who are hyponatraemic, increased serum levels of angiotensin II and renin activity have been reported. In these patients treatment with indomethacin produces an exaggerated pressor effect. ${ }^{11}$ Indomethacin has also been shown to have a direct toxic effect on the kidney, inducing an interstitial nephritis characterized by papillary necrosis, chronic glomerulonephritis, nephrotic syndrome and acute renal failure, ${ }^{13-15}$ although these features were not present in our patient.

In conclusion, we have described the case of a patient with adequate renal function who developed acute life-threatening water intoxication and salt retention on re-exposure to low dose cyclophosphamide in combination with indomethacin, neither of which alone would have been anticipated to cause these problems. Both drugs are administered regularly to out-patients for treatment of various disorders. We suggest that there may be a synergy of action between these two drugs and recommend that they should be used together only with extreme caution.

7. McCarthy, J.T., Tones, V.E., Romero, J.C. et al. Acute intrinsic renal failure induced by indomethacin: role of prostaglandin synthetase inhibition. Mayo Clin Proc 1982, 57: 289-296.

8. Dunn, M.J. \& Zambraski, E.J. Renal effects of drugs that inhibit prostaglandin synthesis. Kidney Int 1980, 18: 609-622.

9. Gerber, J.G., Anderson, R.J., Schrier, R.L.O. \& Nies, A.S. Prostaglandins and the regulation of renal circulation and function. In: Oates, J.A. (ed.) Advances in Prostaglandin, Thromboxane and Leukotriene Research, Vol 10: Prostaglandins and the Cardiovascular System. Raven Press, New York, 1982, pp. 227-254.

10. Kaojarern, S., Chennavasin, P., Anderson, S. \& Brater, D.C. Nephron site of effect of non-steroidal antiinflammatory drugs on solute excretion in humans. Am J Physiol 1983, 244: F134-139. 
11. Dzau, V.J., Packer, M., Lilly, L.S. et al. Prostaglandins in severe congestive failure. Relation to activation of the renin - angiotensin system and hyponatraemia. $N$ Engl $J$ Med 1984, 310: 347-352.

12. Negus, P., Tannen, R.L. \& Dunn, M.J. Indomethacin potentiates the vasoconstriction actions of angiotensin II in normal man. Prostaglandins 1976, 12: 175-180.

13. Finkelstein, A., Fraley, D., Stachura, I. et al. Fenopron nephropathy; lipoid nephrosis and interstitial nephritis: a possible T lymphocyte disorder. Am J Med 1982, 72: $81-87$.
14. Moralos, A. \& Steyn, J. Papillary necrosis following phenylbutazone ingestion. Arch Surg 1971, 103: $420-421$.

15. Wiseman, E.H. \& Reinent, H. Anti-inflammatory drugs and renal papillary necrosis. Agents Actions 1975, 5: 322-325. 